\title{
QUALIDADE DO FIO "OPEN-END" OBTIDO COM MATERIAS-PRIMAS PRODUZIDAS POR VARIEDADES PAULISTAS DE ALGODOEIRO E SUAS MISTURAS COM POLIESTER $(1,2)$
}

JUL:IO ISAO KONDO (3), NELSON PAULIERI SABINO (3), Seção de Tecnologia de Fibras, MIITON GERALDO FUZATTO, Seção de Algodão, Instituto Agronômico, e GILBERTO CAMPANATTI, Serviço de Desenvolvimento de Fiação, Divisāo Têxtil da Rhodia $S A$.

\section{RESUMO}

No presente trabalho, foi avaliada a pontencialidade de duas variedades paulistas de algodoeiro, atualmente em distribuição para plantio no Estado, e o efeito da mistura da sua matéria-prima com fibras sintéticas, representadas pelo poliéster, com respeito às principais características do fio obtido através do novo processo conhecido como "open-end". O algodão utilizado no estudo, proveniente das variedades IAC 17 e IAC 18, foi colhido nas Estações Experimentais do Instituto Agronômico, localizadas em Tietê e Tatuí respectivamente, no ano agrícola de 1978/79. A variedade IAC 18 proporcionou a obtenção de fios "open-end" de melhor qualidade, quando comparada à IAC 17, embora as diferencas nas características do fio produzido não tenham sido tão marcantes quanto aquelas encontradas nas propriedades físicas da fibra. A mistura de poliéster ao algodāo serviu para melhorar as característicals dos fios produzidos, principalmente com relação à tenacidade. As indüstrias de fiação que utilizam esse processo poderão ter uma previsão de qualidade dos fios a serem produzidos com algodões das variedades estudadas, ou com suas misturas com poliéster, através das equaçōes de regresssão apresentadas.

(1) Trabalho apresentado na II Reunião Nacional do Algodão, Salvador (BA), de 9 a 13 de agosto de 1982, e no X Congresso Nacional de Técnicos Têxteis / IX Congresso da Federação Latino-Americana đe Químicos Têxteis, Rio de Janeiro (RJ), de 3 a 7 de setembro de 1982. Recebido para publicação a 11 de janeiro de 1983.

(2) Com apoio financeiro da EMBRAPA.

(3) Com bolsa de suplementação do CNPq. 


\section{INTRODUÇĀO}

O processo de fiação "open-end" elimina algumas fases do processamento industrial, como as da maçaroqueira e da conicaleira, ambas utilizadas no sistema convencional de filatórios a anéis. Tal processo lança mão de rotores que giram a altas velocidades, provocando o retorcimento das fibras individualizadas, para dar formação ao fio. A produção de uma unidade "open-enà" é três a çuatro vezes maior do que a de uma unidade do filatório convencional mais desenvolvido (2).

Os fios "open-end" produzidos diferem dos elaborados nos filatórios convencionais quanto à estrutura e propriedades físicas. Vários fatores ligados ao mecanismo desse processamento das fibras tornam o fio mais fraco, mais volumoso e mais extensível do que o convencional, numa dada torção e título $(3,4,8)$.

Sua perda de resistência pode ser minimizada, fiando-se em títulos mais grossos e com algodões mais curtos. A "open-end" não é recomendada para fios finos obtidos com algodóes de fibra longa (7). Bons resultados para resistência desse fio podem ser conseguidos, utilizando-se fibras de algodão de baixo valor Micronaire e de alta resistência $(\mathbb{1}, 6)$.

O comprimento das fibras de algodão, recomendado atualmente para o processo de fiação "open-end", é aquele compreendido entre 25,0 e $28,0 \mathrm{~mm}$ (Fibrógrafo), correspondente ao produzido na Zona Meridional do Brasil.

Tendo em vista a importância que o processo representa para a indústria têxtil, foi desenvolvido o presente trabalho, objetivando avaliar a potencialidade das matérias-primas produzidas pelas principais variedades paulistas de algodoeiro, assim como das suas misturas com fibras sintéticas (poliéster).

\section{MATERIAL E MÉTODOS}

O algodão utilizado, produzido pelas variedades IAC 17 e IAC 18, foi colhido nas Estações Experimentais do Instituto Agronômico, localizadas em Tietê e Tatuí respectivamente, no ano-agrícola de 1978/79. De cada uma das variedades, foram retiradas 50 amostras de fibras, para a análise das principais características tecnológicas, abaixo relacionadas.

Micronaire: índice determinado no aparelho Fibronaire e que representa a finura da fibra, quando são iguais as condiçōes de maturidade. Quando ambas as condições variam, representa o complexo finura + maturidade. É obtido mediante duas determinaçôes efetuadas em cada amostra. 
Comprimento: valor médio, em milimetros, do comprimento "span 2,5\%", obtido no Fibrógraío Miod. 430, a partir de cinco determinações em cada amostra.

Uniformidade: uniformidade média do comprimento de fibra, baseada no quociente entre os comprimentos "span $50 \%$ " e " $2,5 \%$ " fornecidos pelo Fibrógrafo Mod. 430, multiplicado por 100. É obtida a partir de cinco determinações em cada amostra.

Resistência da fibra: é determinada no aparelho Pressley com espaçador de $1 / 8$ polegada entre pinças, obtido em quatro determinações em cada amostra e expresso na unidade $\mathrm{g} / \mathrm{Tex}$, que representa o peso necessário, em gramas, para romper um fio ou mecha de fibras, de título internacional de 1 Tex $(\mathrm{Tex}=$ peso em gramas de $1.000 \mathrm{~m}$ de material).

Maturidade: índice médio referente à maturidade da fibra, determinado no Fibrógrafo Mod. 430, conforme o método proposto por SABINO et alii (5). E obtido a partir de cinco determinaçōes em cada amostra.

A comparação dos resultados obtidos para as características mencionadas foi realizada através do teste " $t$ ".

A fibra sintética usada para as diferentes misturas com o algodão foi o poliéster, apresentando as seguintes características tecnológicas:

Comprimento de corte da fibra: $32 \mathrm{~mm}$;

Título da fibra: 1,69 dTex;

Tenacidade da fibra: $5,3 \mathrm{~g} / \mathrm{dTex}$;

Alongamento: $21,4 \%$;

Frisagem : 8,5 ondas/centímetro;

Retração da fibra: $3,6 \%$;

Enzimagem : 0,09;

Lustro: semi-opaco.

Os algodóes utilizados, compreendendo para cada variedade três fardos de aproximadamente $200 \mathrm{~kg}$, foram processados individualmente em fiação industrial convencional, constituída de linha de abertura, batedor e carda.

O processo utilizado para o poliéster constou de alimentador de fibra, com formação da manta em dispositivo montado na carda, com saída em fitas. Em seguida, essas fitas de poliéster foram submetidas a uma pré-passagem para homogeneização.

Para a mistura de algodão com poliéster, foram feitas duas passagens no passador, tendo a primeira a finalidade de mistura propriamente dita e, a segunda, de homogeneização, dando produção a fitas de títulos $\mathrm{Ne} 0,15$ e $\mathrm{Ne} 0,16$ respectivamente. 
Tanto as fitas de algodão puro como aquelas compostas por algodão + poliéster foram processadas no filatório "open-end" ZINSER, provido de caixa de fiação Rotomatic SKF A rotação utilizada no cilindro abridor foi 7.000 r.p.m e, no rotor, 45.000 r.p.m. Os fios produzidos tiveram título $\mathrm{Ne} 16$.

As percentagens das misturas de algodão com poliéster, assim como os níveis de torção utilizados, podem ser observados na relação abaixo :

Algodão/Poliéster ( $\%) \quad$ Coeficientes de torção $\left(\alpha_{\mathrm{e}}\right)$

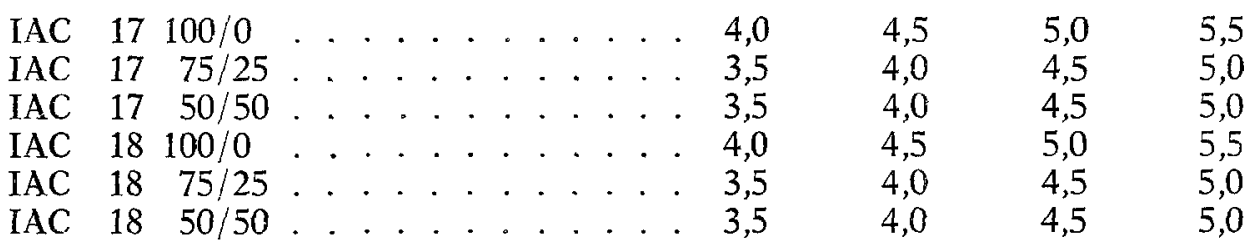

Após o processamento dos fios, foram retirados quatro cones, sempre dos mesmos rotores, correspondentes a cada nível de mistura e coeficiente de torção utilizados, os quais foram analisados, levando-se em consideração as seguintes características:

Título: caracteriza a relação existente entre peso e comprimento do fio. Foi empregado o sistema indireto de titulação inglesa e 40 determinações por amostra

Resistência do fio em meadas: índice baseado em testes de tração em meadas de 120 jardas, expresso em coeficiente de resistência (CS), que corresponde ao produto do valor de ruptura da meada de fios, expresso em libras, pelo título do fio ( $\mathrm{Ne}$ ).

Resistência do fio singelo: índice baseado em testes de tração do fio individual de $0,5 \mathrm{~m}$ de comprimento, expresso em RKM, que representa o comprimento, em quilômetros, do fio, necessário para provocar a ruptura em razão do seu próprio peso. As determinações foram feitas no aparelho Dynamat II acoplado a um minicomputador de processamento de testes e cálculos dos resultados.

Elongação do fio: valor médio, baseado em testes de tração do fio individual de $0,5 \mathrm{~m}$, expresso em percentagem, obtido no ponto de ruptura, simultaneamente com o valor da resistência de ruptura, no aparelho Dynamat II.

Irregularidade Uster (U\%): valor médio, lido diretamente no galvanômetro do integrador, e que representa a indicação quantitativa da irregularidade linear registrada pelas variações medidas no regularímetro. O regularímetro Uster dá a indicação contínua de um valor 
proporcional do peso por unidade de comprimento de qualquer material têxtil de fiação. A velocidade utilizada no regularímetro foi $25 \mathrm{~m} / \mathrm{minuto}$ e cinco minutos para cada teste, com sensibilidade de $\pm 100 \%$

Indicador de imperfeições: é um equipamento auxiliar que efetua a contagem dos pontos finos, pontos grossos e "neps" em combinação simultânea com o funcionamento do regularímetro Uster. Convencionalmente, o número dos pontos e os "neps" são expressos para 1.000 metros de fio.

Pontos finos: é a indicação que corresponde aos pontos dessa natureza, abaixo de um limite de controle determinado, o qual foi fixado em $50 \%$ do valor da seção média do fio.

Pontos grossos: é o valor que representa os pontos grossos, quando ultrapassa o limite de controle. Foi utilizada a escala 3 que corresponde ao limite de controle de 50\%. "Neps": valor que leva em consideração apenas o peso por unidade de comprimento fixo, de modo que não há possibilidade de confundir com ponto grosso e vice-versa. Foi utilizada a escala 3, de maneira que um "neps" apresenta uma seção acima de $200 \%$ do limite de controle no intervalo de comprimento de um milímetro do fio.

A análise dos resultados obtidos para as diferentes características do fio "open-end" foi feita com base no método de regressão múltipla, para expressar o grau de associação das variáveis independentes (coeficiente de torção e percentagem de algodão na mistura) com determinada variável dependente (resistência, elongação, pontos grossos, pontos finos e "ncps"). Foi utilizado o teste $\mathbf{F}$ para análise das equações de regressão obíidas.

$$
\begin{aligned}
& \text { foi o seguinte: } \\
& \qquad Y=b_{0}+b_{1} X_{1}+b_{2} X_{2}+b_{11} X_{1}+b_{22} X_{2}+b_{12} X_{1} X_{2}
\end{aligned}
$$

O modelo matemático inicial de regressão múltipla utilizado

onde $\mathrm{X}_{1}$ representa o coeficiente de torção e, $\mathrm{X}_{2}$, a porcentagem de algodão na mistura. Essa equaçâo foi modificada em alguns casos pela eliminação de termos que não apresentaram efeitos significativos.

\section{RESULTADOS E DISCUSSĀo}

Os resultados médios das principais características tecnológicas, assim como os valores do teste " $t$ " e coeficientes de variação, encontram-se no quadro 1 . Pode-se observar que a variedade IAC 18 superou a IAC $17 \mathrm{em}$ todas as propriedades físicas da fibra.

Nos quadros 2 e 3 , estão os valores médios para as características de fios "open-end", relativos às variedades IAC 17 e IAC 18, respectivamente, assim como às misturas de cada uma delas com poliéster (PES). 
QUADRO 1 - Resultados médios, coeficientes de variação (CV) e teste "t" das principais características tecnológicas das fibras, obtidos para as variedades 'IAC 17 ' e 'IAC 18', relativos a 50 amostras do algodão utilizado para a realização de testes em fiação "open-end"

\begin{tabular}{|c|c|c|c|}
\hline \multirow{2}{*}{ Características } & \multicolumn{2}{|c|}{ Variedade } & \multirow{2}{*}{$\begin{array}{c}\text { Teste "t" } \\
\text { IAC } 17 \times \text { IAC } 18\end{array}$} \\
\hline & IAC 17 & IAC 18 & \\
\hline Indice Micronaire . . . . . & 4,39 & 4,57 & \multirow{2}{*}{$9,99 \div$} \\
\hline $\mathrm{CV}(0)$ & 2,16 & 1,86 & \\
\hline Comprimento "span 2,5\%" (nin) .. & 26,34 & $2 \pi, 43$ & \multirow{2}{*}{$14,99 \div$} \\
\hline $\mathrm{CV}(0) \ldots$ & 1,27 & 1,17 & \\
\hline Uniformidade de comprimento (\%) & 46,09 & $\varsigma 7,53$ & \multirow{2}{*}{$9,87^{* *}$} \\
\hline$C V(0 \%)$ & 1,49 & 1,62 & \\
\hline Resistência (Pressley 1/82) (g/Tex) & 21,09 & 22,76 & \multirow{2}{*}{$13,79 \div$} \\
\hline $\mathrm{CV}(\%)$ & 3,18 & 2,34 & \\
\hline Maturidade $\left(\mathbb{M}^{0} \%\right)$ & $57, \pm 6$ & 5120 & \multirow{2}{*}{$7,51 \% *$} \\
\hline $\mathrm{CV}(\%)$ & 4,55 & 3,86 & \\
\hline
\end{tabular}

( $\left.{ }^{*}\right)$ Significativo ao nivel de $1 \%$.

A equação de regressão, baseada no modelo matemático proposto, foi utilizada para as seguintes variáveis dependentes: coeficiente de resistência (CS), número de "neps"/1.000m, tenacidade (RKM) e elongação do fio (\%). Para as demais, tendo ocorrido a eliminação de alguns termos da equação original, por não apresentarem valores signifi. cativos, foram utîlizadas as seguintes equações:

$$
\mathrm{Y}=\mathrm{b}_{0}+\mathrm{b}_{1} \mathrm{X}_{1}+\mathrm{b}_{2} \mathrm{X}_{2} \text {, para númerc de pontos grossos/1.000m e }
$$

$\mathrm{Y}=\mathrm{b}_{0}+\mathrm{b}_{2} \mathrm{X}_{2}$ para irregularidade Uster $(\mathrm{U} \%)$ e número de pontos finos $/ 1.000 \mathrm{~m}$.

Foram obtidas, portanto, quatorze equações de regressão, envolvendo diversas possibilidades de misturas do algodão das duas variedades com o poliéster, e que são apresentadas no quadro 4, acompanhadas 


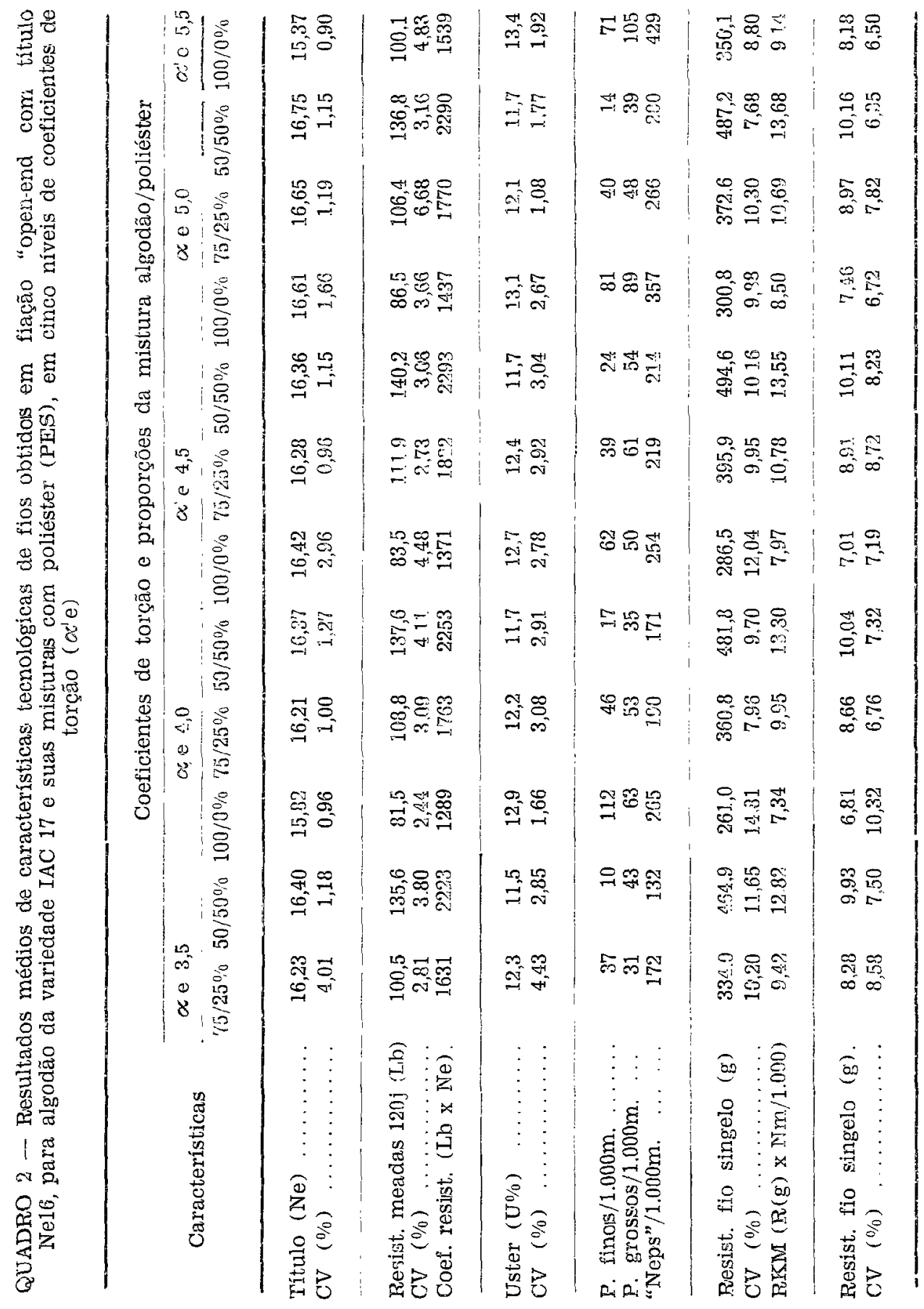




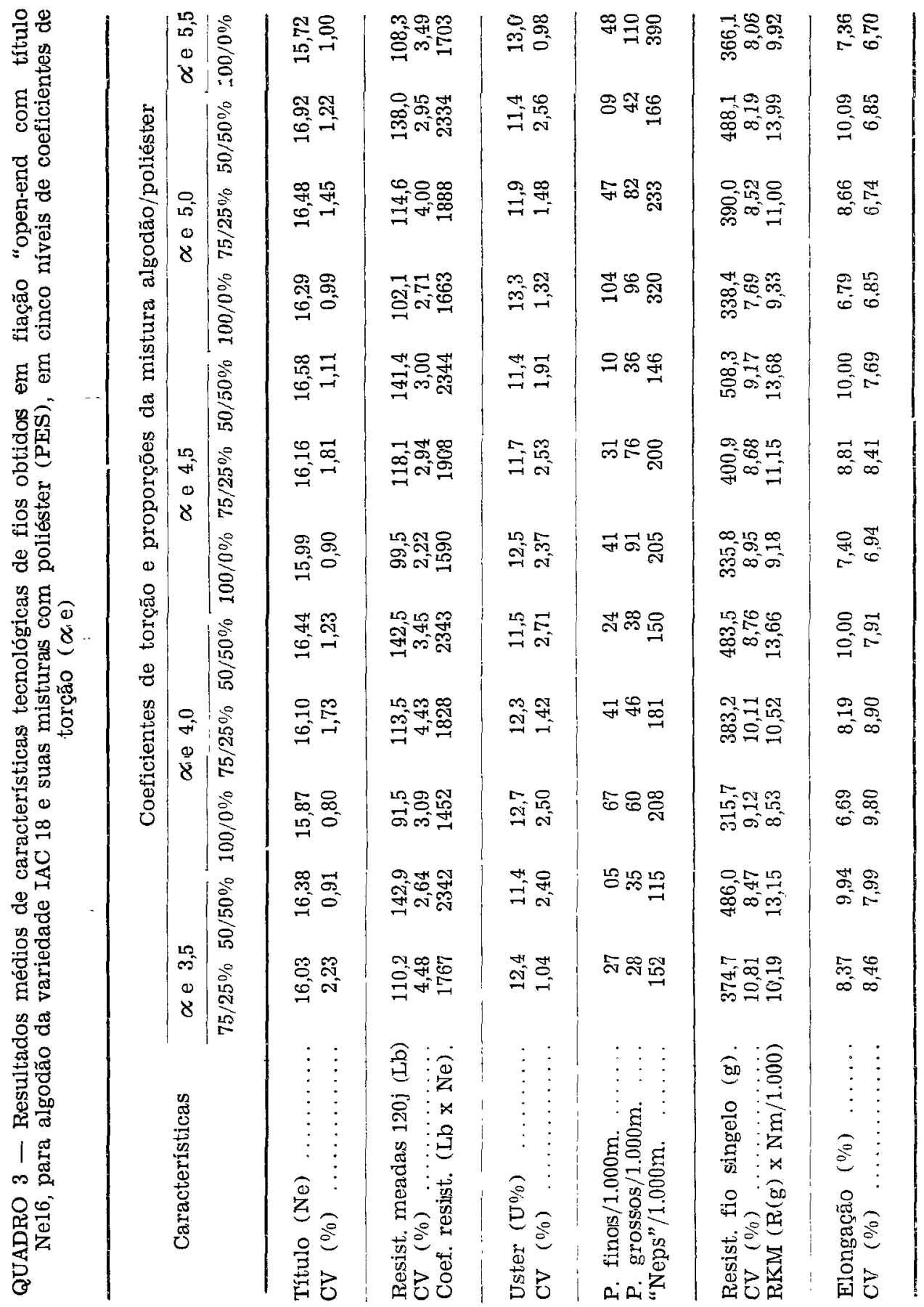


dos respectivos valores de correlação múltipla $\left(\mathrm{R}^{2}\right)$ e de $\mathbf{F}$ múltiplo. Observa-se que todos os valores deste último são significativos ao nível de $1 \%$.

Com a finalidade de visualizar a variação das características do fio, em função das variáveis independentes, foram constituídas as superfícies planas de resposta e as linhas de regressão apresentadas nas figuras 1 a 12 .

Com relação à resistència do fio em meadas de 120 jardas, as figuras 1 e 2 mostram que, aumentando a percentagem de fibra de poliéster na mistura, com consequiente diminuição da percentagem de algodão, obtém-se aumento no coeficiente de resistência do fio. Por outro lado, consegue-se aumento nesse coeficiente, aumentando-se o coeficiente de torção, e esse aumento foi tanto maior quando mais algodão existia na mistura Na mistura de $50 \%$ de algodão com $50 \%$ de poliéster, praticamente não se verificou variação dessa característica em função do coeficiente de torção.

Com respeito à resistência do fio singelo, as figuras 3 e 4 mostram, da mesma forma, que, aumentando a percentagem de fibra de poliéster na mistura, obtém-se aumento da tenacidade do fio. Também, aumentando o nível do coeficiente de torção, obtém-se aumento no coeficiente RKM, sendo esse aumento tanto maior quanto maior a participação de algodão na mistura. Também nesse caso, na mistura com $50 \%$ de cada material, o aumento do RKM foi muito pequeno, em função do coeficiente de torção.

As figuras 5 e 6 mostram aumento na elongaçāo do fio com aumento de percentagem de fibra de poliéster na mistura. Aumentando o coeficiente de torção, obtém-se aumento na elongação: esse efeito foi maior no caso da variedade IAC 17, principalmente na composição $100 \%$ algodão. Para a mistura com 50\% de cada material, no caso dessa variedade ainda se verificou efeito, embora menor, da torção sobre a elongação do fio. Entretanto, para essa mistura com algodão da IAC 18 , tal efeito é praticamente inexistente.

Pela figura 7 , verifica-se que, aumentando a percentagem de algođão na mistura, a irregularidade Uster (U\%) aumenta. A comparação entre as variedades mostra que, para as mesmas composições da mistura, a irregularidade foi sempre maior quando o algodão era proveniente da IAC 17.

Como se verifica pela figura 8 , os pontos finos $/ 1.000 \mathrm{~m}$ aumentam com a elevação da percentagem de algodão na mistura. $O$ número de pontos finos foi maior na IAC 17 e a diferença entre as variedades foi maior, à medida que crescia a proporção de algodão na mistura. Para as misturas de 50\% de cada material, não houve diferenças entre as variedades. 


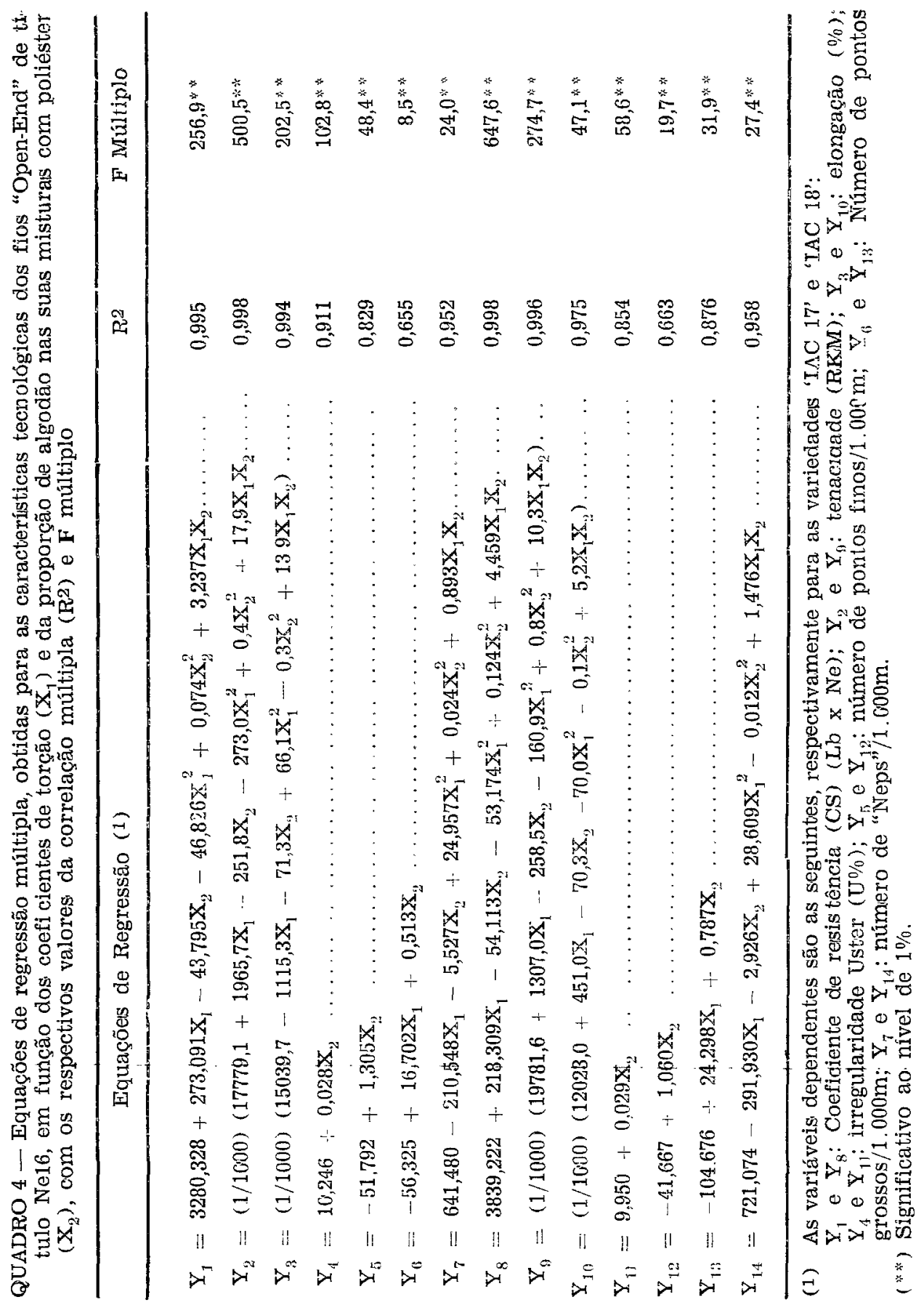




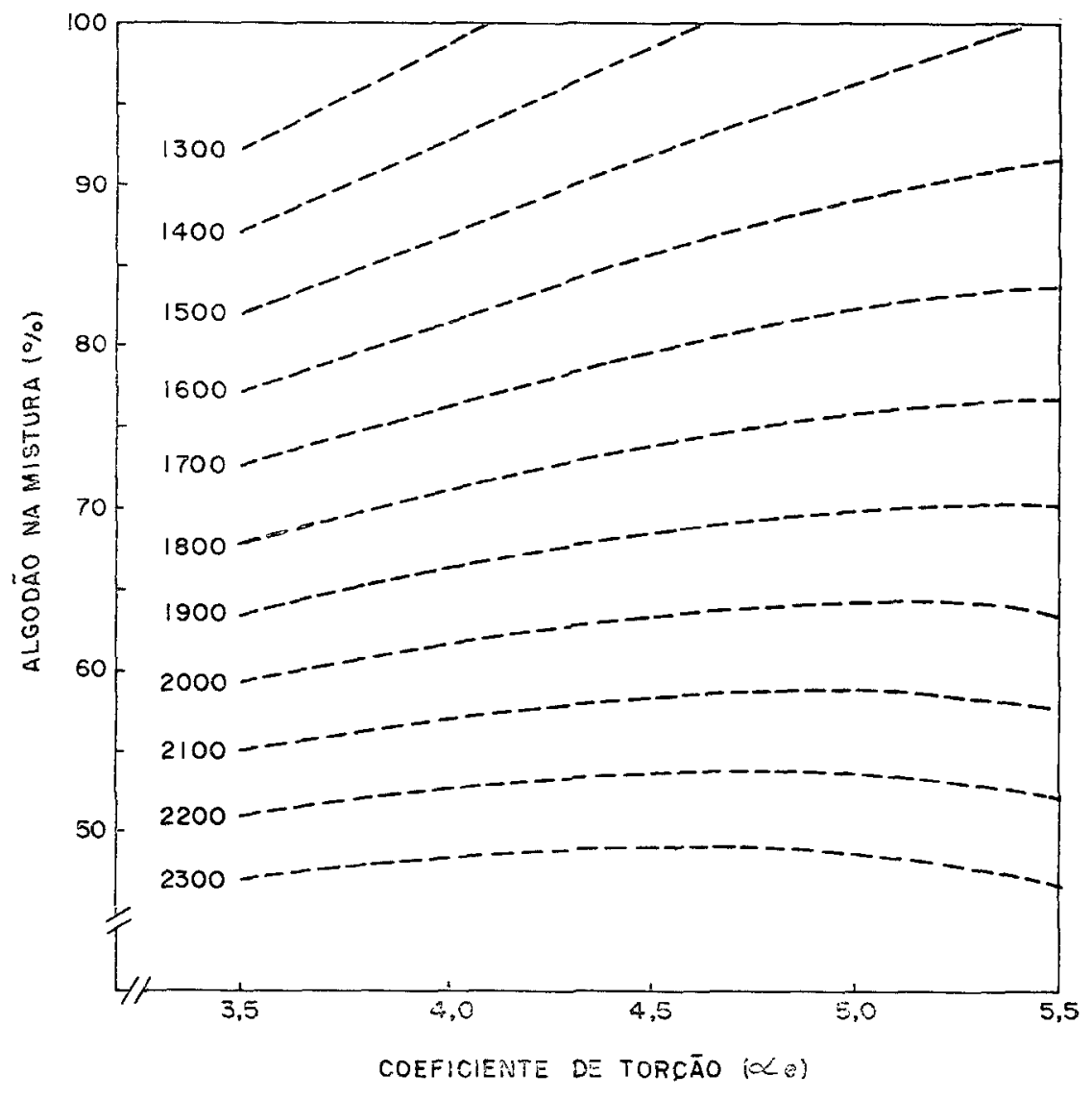

FIGURA 1 - Superfície de resposta mostrando a variação do coeficiente de resistência do fio "open-end" ( $\mathrm{Lb} \times \mathrm{Ne}$ ) de título $\mathrm{Ne} 16$, em funçãc da propor. ção de algodão na sua mistura com poliéster e do coeficiente de torção, no caso da variedade IAC 17 


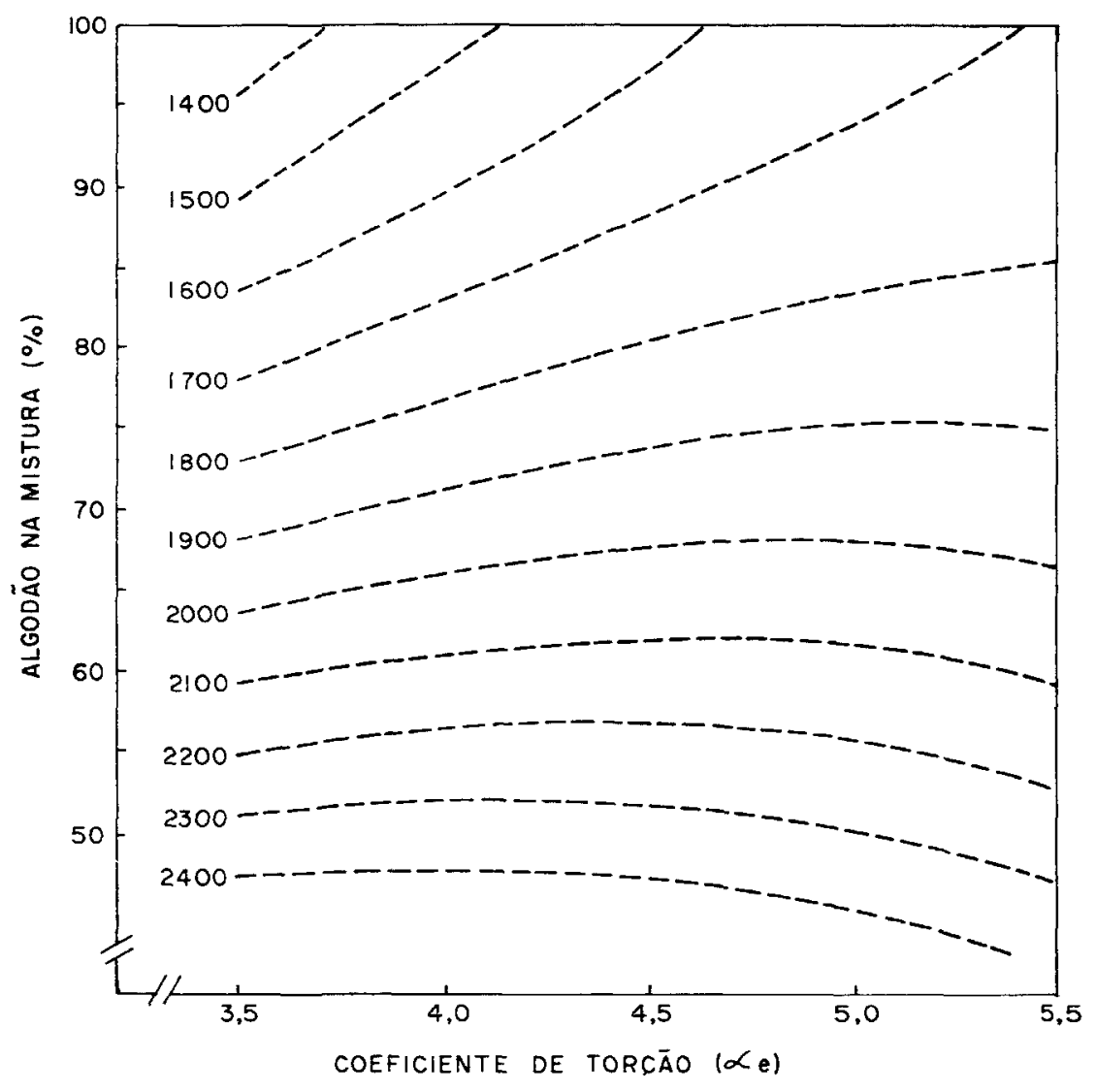

FIGURA 2 - Superfície de resposta mostrancio a variação do coeficiente de resis. tência do fio "open-end" ( $\mathrm{Lb} \times \mathrm{Ne}$ ) de título Ne 16, em função da proporção de algodão na sua mistura com poliéster e do coeficiente de torção, no caso da variedade IAC 18. 


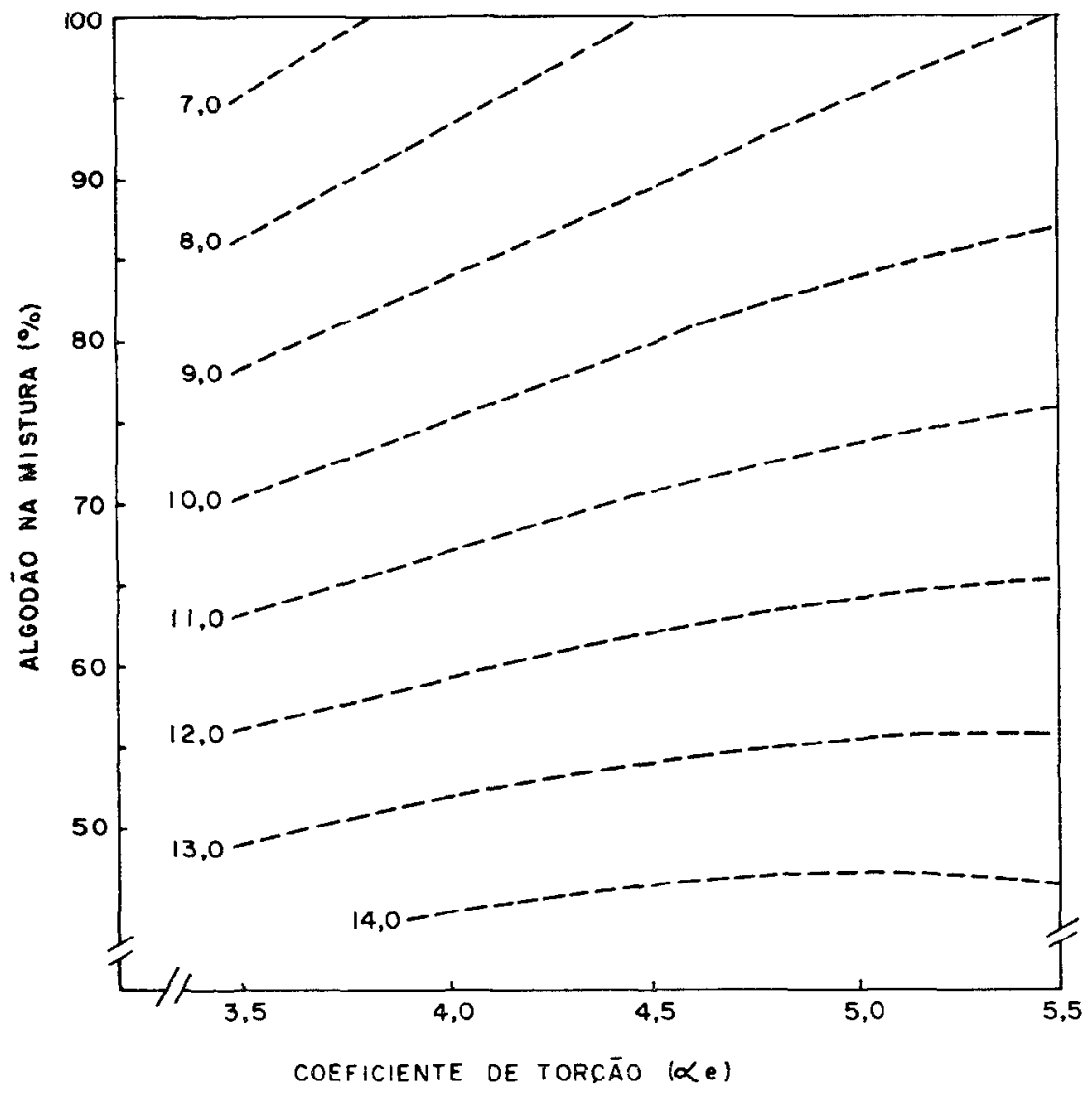

FIGURA 3 - Superfície de resposta mostrando a variaçāo da tenacidade do fio "open-end" (RKM) de título $\mathrm{Ne} 16$, em função da proporção de algodão na sua mistura com poliéster e do coeficiente de torção, no caso da variedade IAC 17. 


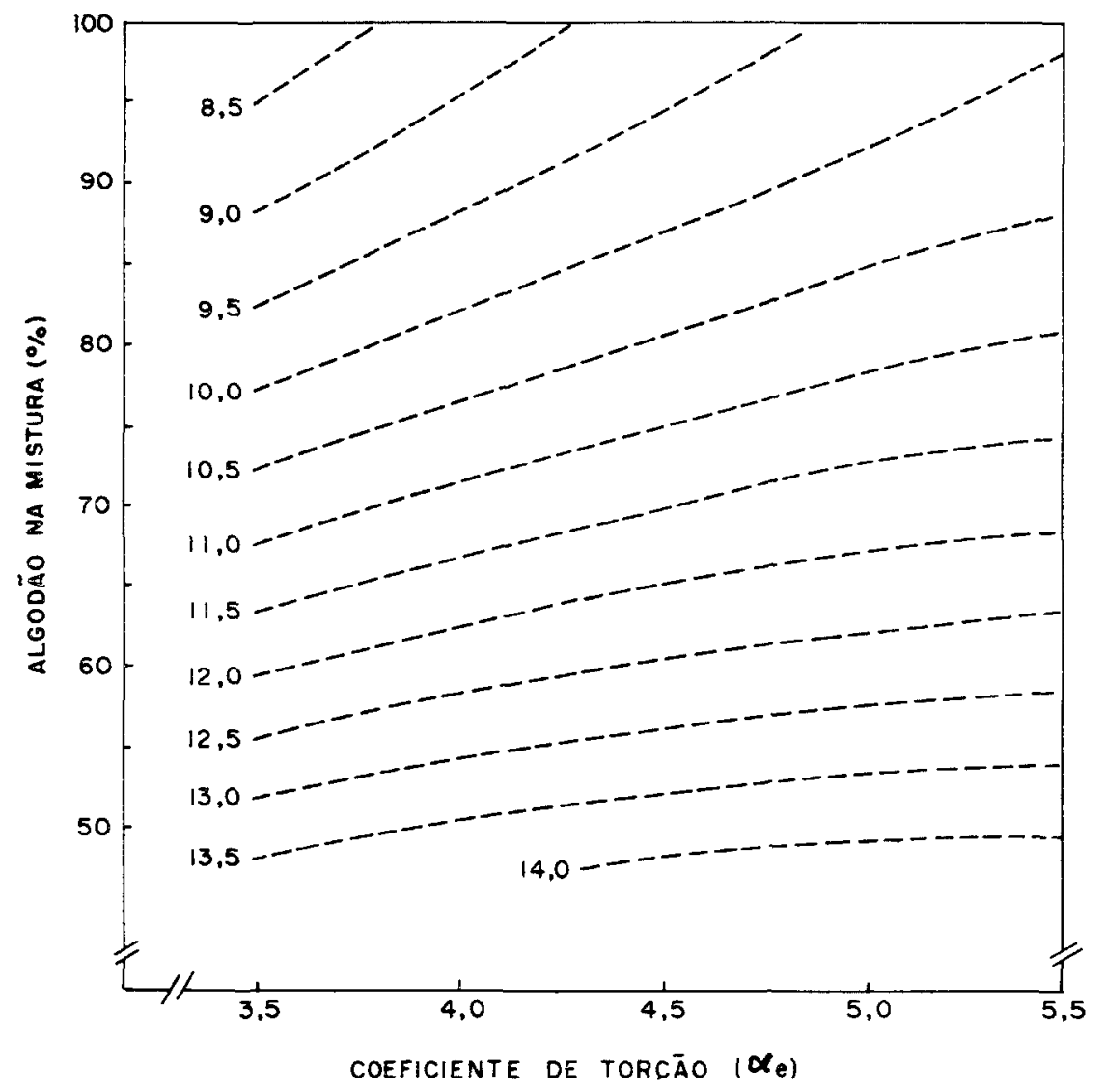

FIGURA 4 - Superfície de resposta mostrando a variação dá tenacidade do fio "open-end" (RKM) de título Ne 16, em função da proporção de algodão na sua mistura com poliéster e do coeficiente de torção, no caso da variedade IAC 18 . 


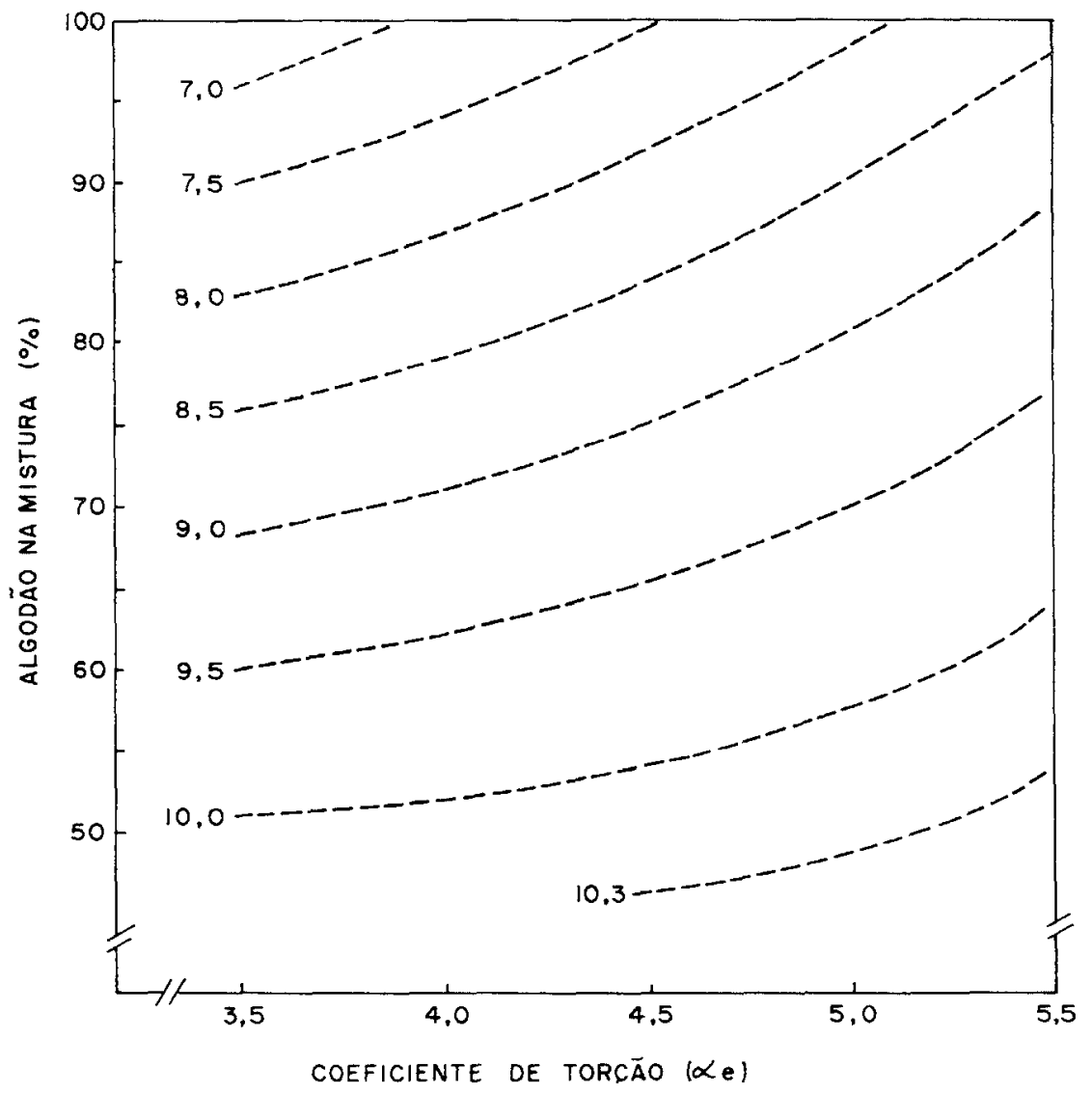

FIGURA 5 - Superfície de resposta mostrando a variação da elongação do fio "open-end" ( $\%)$ de título Ne 16, em função da proporção de algodão na sua mistura com poliéster e do coeficiente de torção, no caso da variedade IAC 17. 


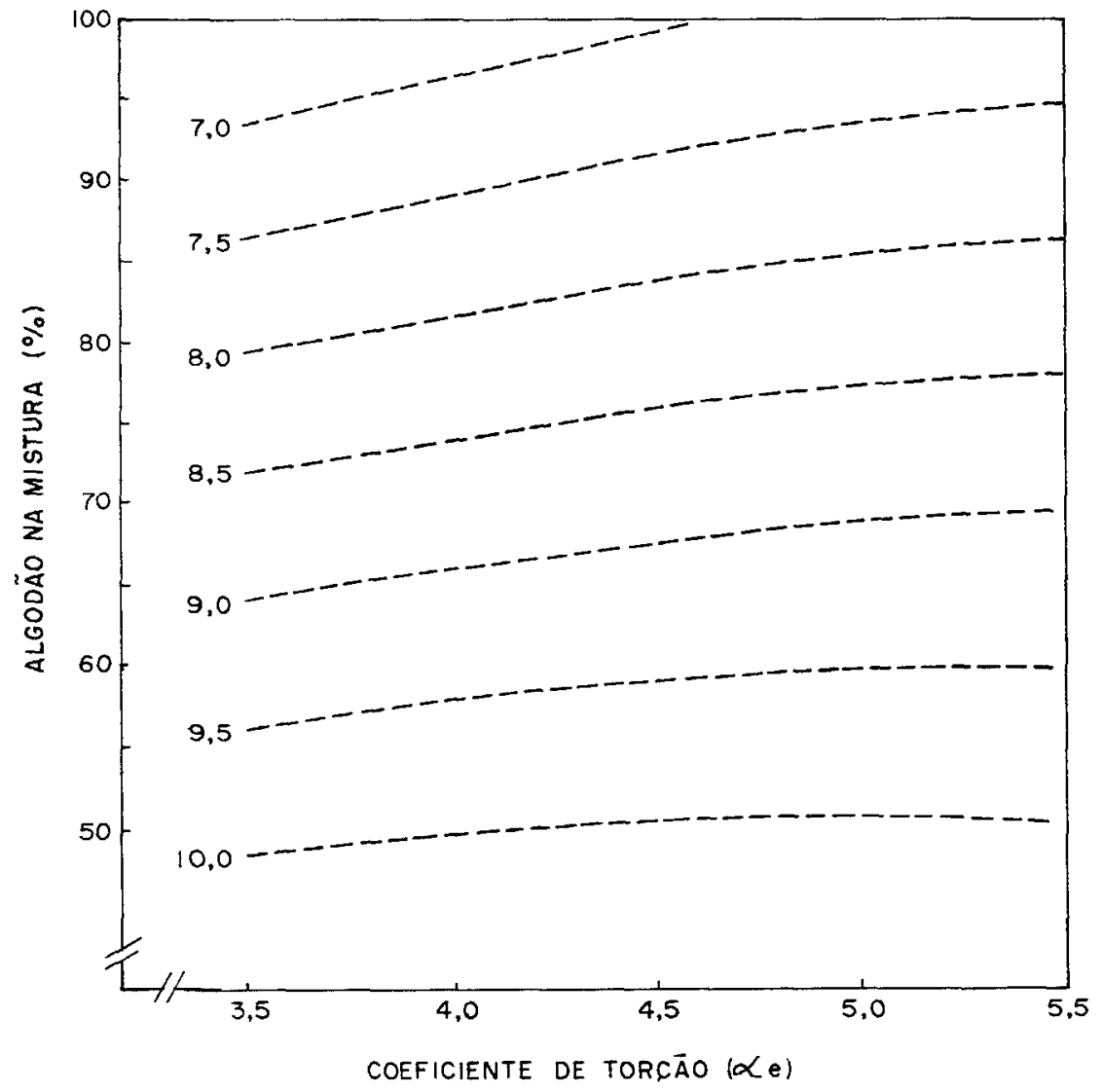

FIGURA 6 - Superfície de resposta mostrando a variação da elongação do fio "open-end" $(\%)$ de título Ne 16 , em função da proporção de algodão na sua mistura com poliéster e do coeficiente de torção, no caso da variedade IAC 18. 


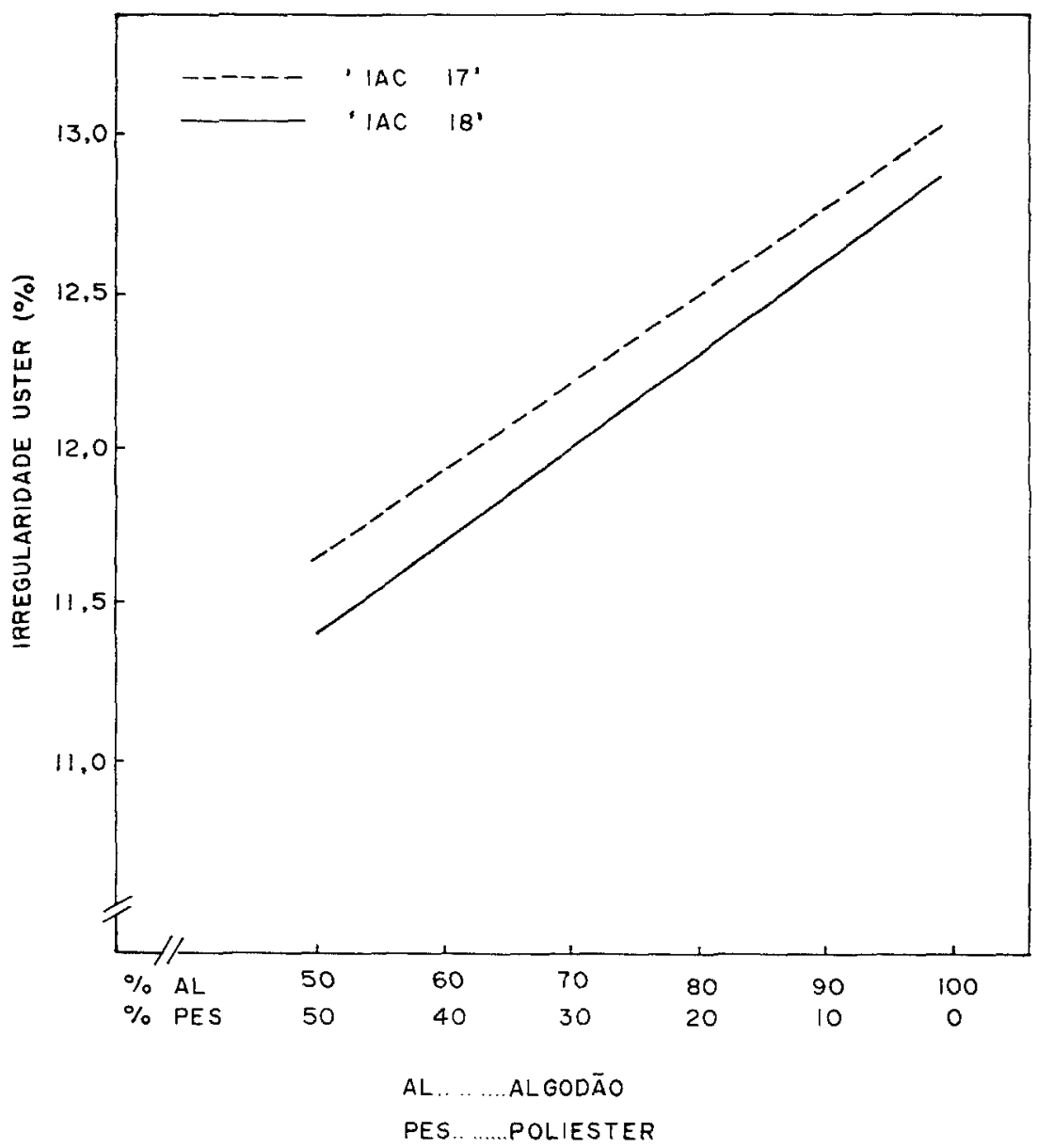

FIGURA 7 - Representação gráfica da equação de regressão do fio "open-end" de título $\mathrm{Ne} 16$, mostrando a variação da irregularidade Uster (U\%) em função áa composição das misturas de algodão (AL) e poliéster (PES), para as duas variedades estudadas. 


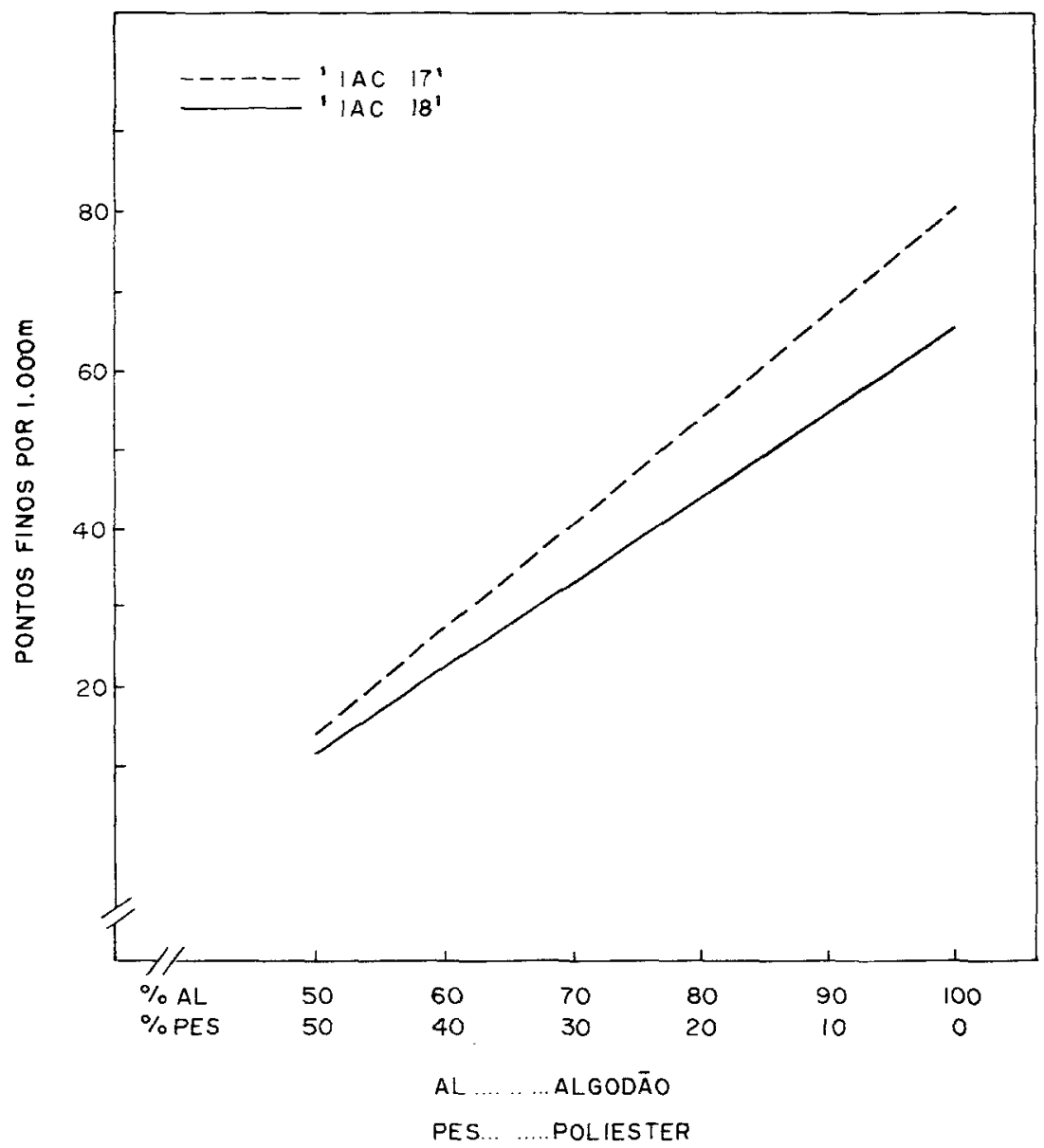

FIGURA 8 - Representaçấo gráfica da equação de regressão do fio "open-end" de título Ne 16, mostrando a variação do número de pontos finos $/ 1.000 \mathrm{~m}$ em furção da composição das misturas de algodão (AL) e poliéster (P), para as cuias variedades estudadas. 


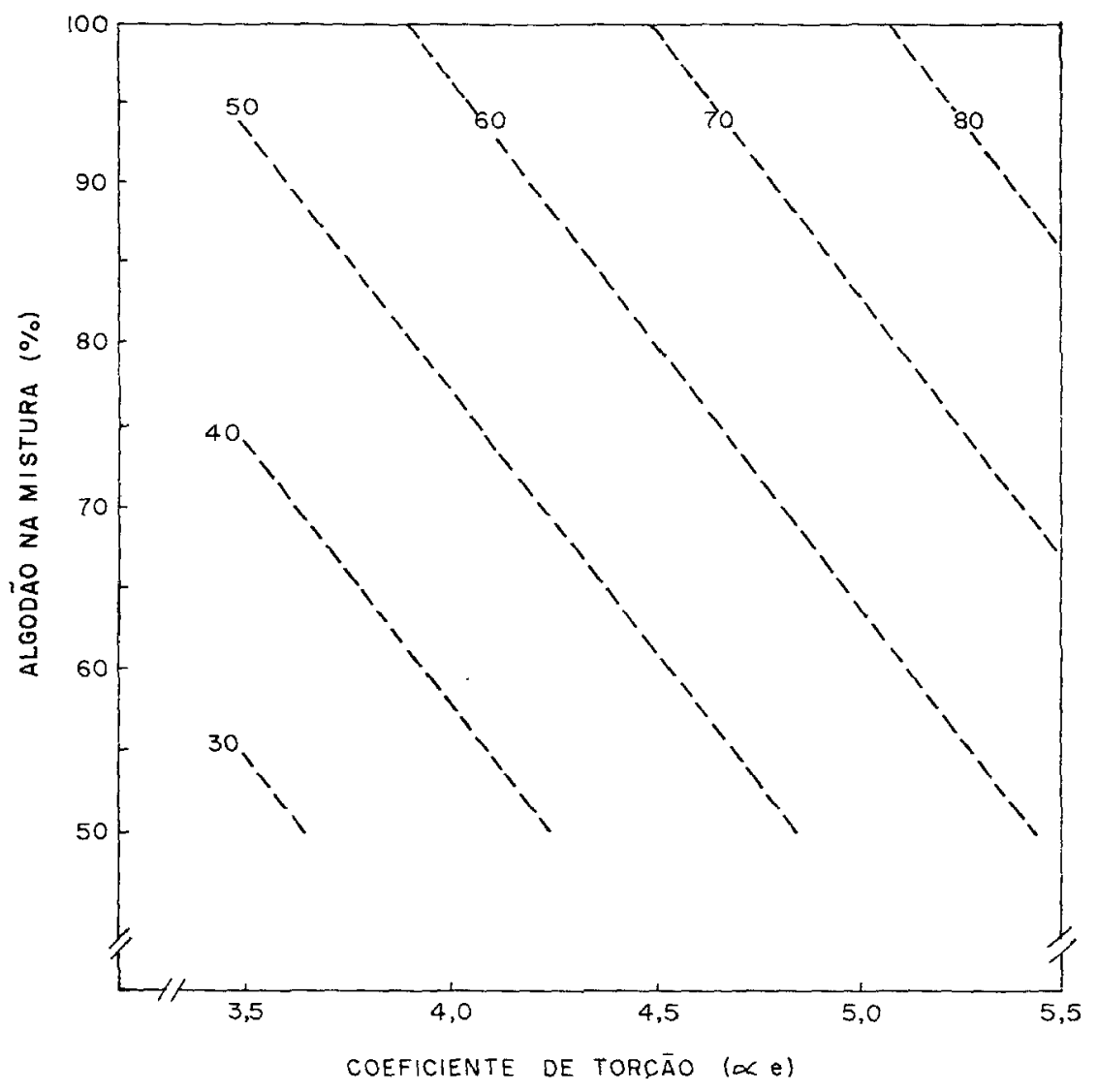

ETGURA 9 - Superfície de resposta mostrando a variação do número de pontos grossos $/ 1.000 \mathrm{~m}$ do fio "open-end" de título Ne 16, em função da proporção de algodão na sua mistura com poliéster e do coeficiente de torção, no caso da variedade IAC 17. 


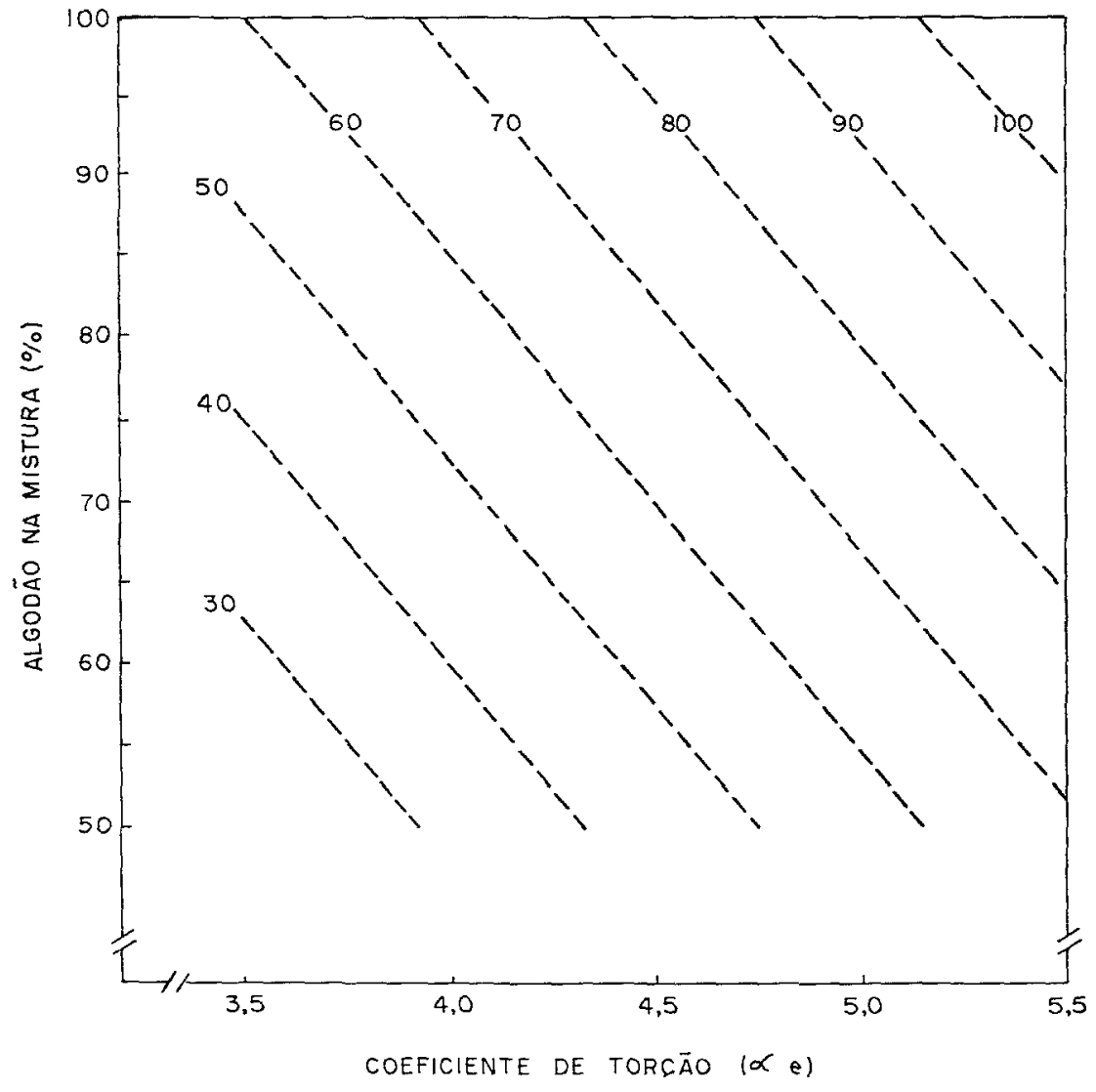

FIGURA 10 - Superfície de resposta mostrando a variação do número de pontos grossos $/ 1.000 \mathrm{~m}$ do fio "open-end" de título Ne 16 , em função da proporção de algodão na sua mistura com poliéster e do coeficiente de torção, no caso da variedace IAC 18 . 


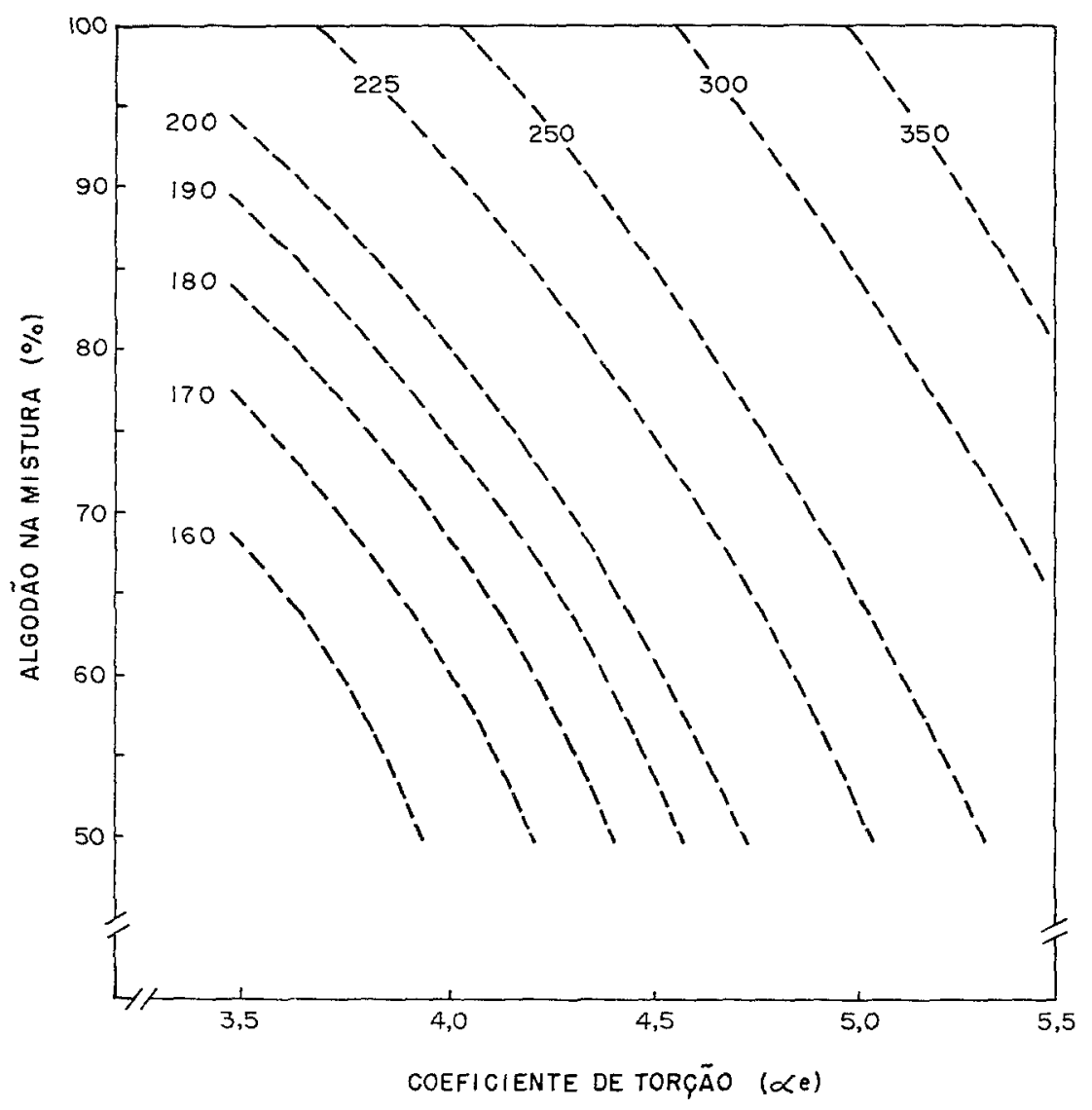

FTGURA 11 - Superfície de resposta mostrando a variação do número de "neps"/ $1.000 \mathrm{~m}$ do fio "open-end" de título $\mathrm{Ne} 16$, em função da proporção de algodão na sua mistura com poliéster e do coeficiente de torção, no caso da variedade IAC 17. 


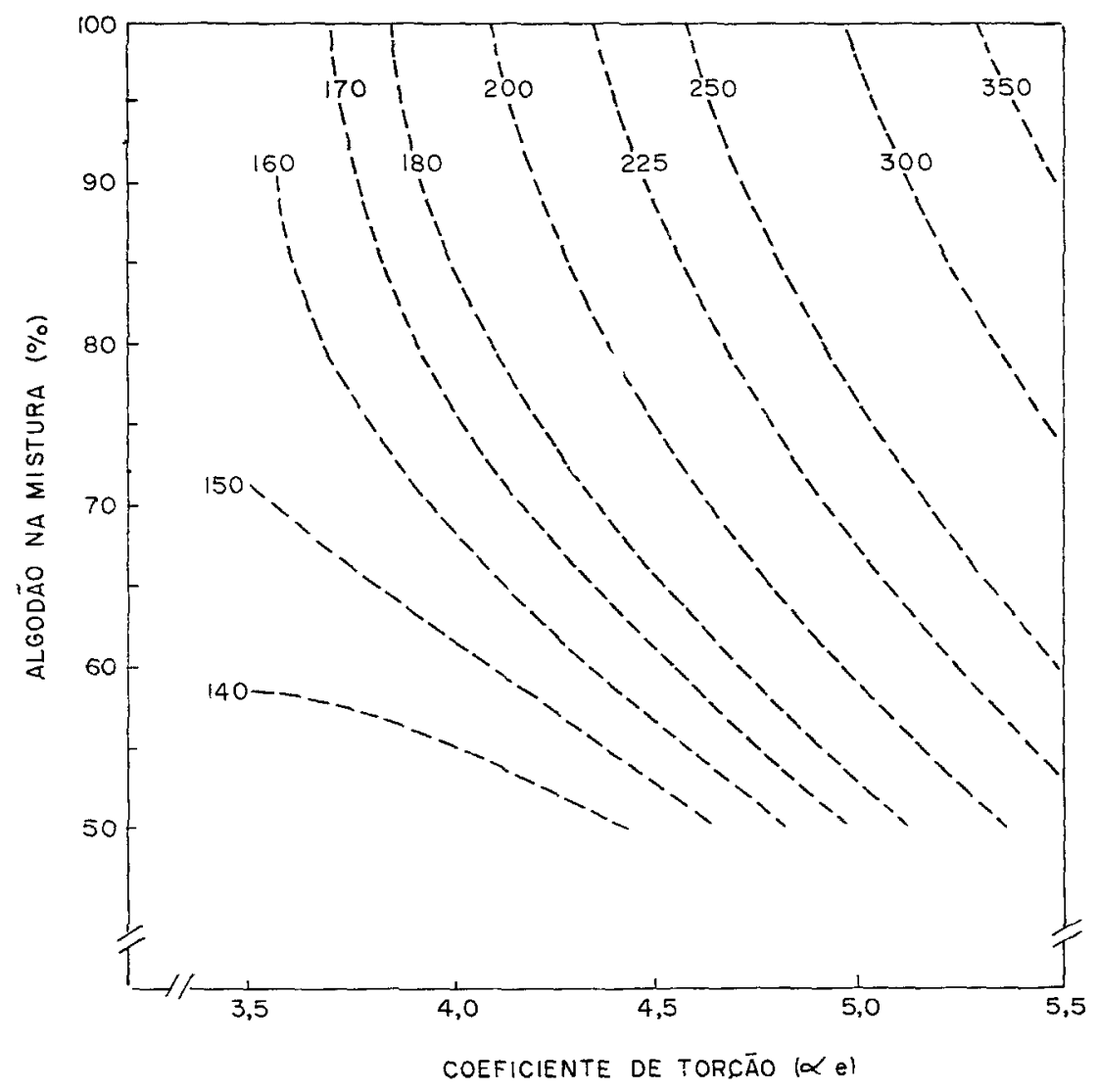

FIGURA 12 - Superfície de resposta mostrando a variação do número de "neps"/ $1.000 \mathrm{~m}$ do fio "open-end" de título $\mathrm{Ne} 16$, em função da proporção de algodão ra sua mistura com poliéster e do coeficiente de torção, no caso da variedade IAC 18. 
As figuras 9 e 10 mostram aumento no número de pontos grossos $/ 1.000 \mathrm{~m}$, tanto com o aumento da percentagem de algodão na mistura como com o aumento do coeficiente de torção. Em linhas gerais, quando o algodão proveio da IAC 18 , observou-se maior número de pontos grossos $/ 1.000 \mathrm{~m}$.

Por outro lado, a mistura com algodão da IAC 17 apresentou maior número de neps $/ 1.000 \mathrm{~m}$ do que aquela com material da IAC 18.

Como se nota pelas figuras 11 e 12 , o número de neps $/ 1.000 \mathrm{~m}$ aumenta com o aumento da percentagem de algodão na mistura, verificando-se o mesmo com o aumento do coeficiente de torção.

\section{CONCLUSÕES} conclusões :

Os resultados obtidos neste trabalho permitiram as seguintes

1. A variedade IAC 18 proporcionou a obtenção de fios "open-end" de melhor qualidade, comparada à IAC 17, embora as diferenças nas características do fio produzido não tenham sido tão marcantes quanto aquelas encontradas nas características da fibra.

2. A mistura de poliéster ao algodão melhorou a qualidade dos fios "open-end" produzidos, com relação a todas as características de fio estudadas, notadamente quanto à tenacidade.

3. As indústrias que empregam o processo de fiação “openend" podem ter uma previsão da qualidade dos fios produzidos com algodões das variedades IAC 17 e IAC 18 ou com suas misturas com a fibra de poliéster utilizada nos estudos, a partir das equações de regressão obtidas.

4. O presente estudo sugere que outros trabalhos devam ser realizados nesse campo, a fim de observar o comportamento de novas variedades de algodão IAC, com respeito às características tecnológicas da fibra e do fio "open-end".

\section{SUMMARY}

\section{OPEN-END SPUN YARN QUALITY OBTAINED WITH RAW MATERIALS PRODUCED BY SÃO PAULO COTTON VARIETIES AND BY BLENDING THEM WITH POLYESTER}

In the present paper it was appraised the potential of two são Paulo cotton varieties (distributed for planting in the State of São Paulo, Brazil) and the effect of its raw material blended with sintetic fiber represented by polyester, concerning to the main characteristics of yarn obtained by the new process known Open-End Spinning. The cotton utilized in this study, came from IAC 17 and IAC 18 varieties, which were harvested at the Experimental Stations of Instituto Agronomico, situated in Tietê and Tatui, respectively during the $1978 / 79$ growing season. With the IAC 18 variety was obtained Open-End yarn of the 
best quality when compared with IAC 17 variety. The differences on yarn characteristics were not so marking as those founded in physics properties of fiber. The blend of polyester to cotton utilized, improved the characteristics of the yarn, mainly in relation to tenacity. The spinning industries that utilize this process, can forecast the quality of yarns to be produced by using the cotton studied, or blends with polyester, through the regresision equations presented.

\section{REFERÊNCLAS BIBLIOGRAFICAS}

1. COTTON, fiber properties and open-end spinning. Textile Topics, Lubbock, Texas, $3(6): 1,1975$.

2. KRAUSE, H. W. \& SOLIMAN, H. A. Openend spinnig - The problem of fiber opening and yarn formation. Textile Research Journal, 41:101-108, 1971.

3. LORD, P. R. The structure of open-end spun yarn. Textile Research Journal, 41:778-784, 1971.

4. — \& GRANDY, P. L. The twist structure of open-end yarns. Textile Resarch Journal, 46:123-129, 1976.

5 SABINO, N. P.; GRIDI-PAPP, I. L.; KONDO, J. I.; CARNEIRO, J. B Maturidade da fibra de algodão determinada pelo fibrógrafo modelo 430 . Bragantia, Campinas, 30:69-77, 1980.

6. SIMPSON, J. \& MURRAY, M. F. Effect of cotton fiber fineness and strength on mechanical processing and open-end spinning and yarn properties. Textile Research Journal, 48:270-276, 1978.

7. SULTAN, M. A. \& EL-HAWARY, I. A. A comparison of the properties of open-end-spun and ring-spun yarns produced from two Egyptian CottonsSultan and El-hawary. Journal of the Textile Institute, 65:194-199, 1974.

8 TOOKA, T. Open-end spinning's current position and outlook; open-end spining. L'Inđustrie Textile, n. 1012:371-375, n. 1013:459-463, 1972. 